\title{
Prediction of postmenopausal status in premenopausal early stage breast cancer patients after adjuvant chemotherapy
}

\begin{abstract}
Introduction: Chemotherapy; a well-known modality for treatment of breast cancer, has an effect on ovarian functions as it can induce premature ovarian failure and chemotherapy induced amenorrhea (CIA). This CIA has an impact on treatment decision.
\end{abstract}

\begin{abstract}
Aim of the study: Predict the postmenopausal status in premenopausal, early-stage breast cancer patients, after receiving adjuvant chemotherapy, to evaluate the possibility of using aromatase-inhibitors in those patients.
\end{abstract}

Methods and material: In this study the changes in serum levels of estradiol ( $\left.\mathrm{E}_{2}\right)$ and follicular-stimulating hormone (FSH) was observed in 50 early breast cancer patients in Medical Research Institute at Alexandria, who developed CIA. The $\mathrm{E}_{2}$ and FSH levels in those patients was measured three times; once CIA was recorded, then after six month, then after one year, and correlated with menstrual history at each visit, and then the collected data were presented in tables and figures, with statistical analysis of these data.

Results: The $\mathrm{E}_{2}$ levels decreased once CIA was recorded then it increased after 6months and still increased after one year of follow-up, while the levels of FSH increased once the amenorrhea was recorded and it decreased after 6 months and one year of follow-up, the hormonal profile of patients who developed CIA was similar to that of patients who suffer from primary ovarian failure, and patients who had a serum $\mathrm{E}_{2}$ below $20 \mathrm{pg} / \mathrm{ml}$ and/or FSH $40 \mathrm{IU} / \mathrm{L}$ or more once the CIA was recorded will not regain menses again after one year of follow-up.

Conclusion: Serum levels of estradiol $\left(\mathrm{E}_{2}\right)$ and follicular-stimulating hormone (FSH) could be used to predict the postmenopausal status in premenopausal early stage breast cancer patients after receiving adjuvant chemotherapy.

Keywords: early breast cancer, chemotherapy, amenorrhea
Volume 5 Issue 6 - 2017

\author{
Osama H Elzaafarany \\ Department of Cancer Management and Research,Alexandria \\ University, Egypt
}

\begin{abstract}
Correspondence: Osama H Elzaafarany, Clinical Oncologist, Assistant Lecturer (Instructor) of Oncology, Medical Research Institute Hospital, Alexandria University, Cancer Management and Research Department, 165th El-Horreya Avenue, ElHadarah, Alexandria, 2156I- Egypt, Fax (+20) 3-421-3719, Tel (+20) 100-355-9455, (+20) 3-420-2900, Email ossama I@alexu.edu.eg
\end{abstract}

Received: October 31, 2017 | Published: December 27, 2017
Abbreviations: CIA, chemotherapy induced amenorrhea; FSH, follicular-stimulating hormone; DFS, disease-free survival; OS, overall survival; GnRH, gonadotropin-releasing hormone; ATAC, arimidex, tamoxifen, alone or in combination; ER, estrogen receptor; CMFPT, cyclophosphamide, methotrexate, flurouracil, prednisilone, tamoxifen

\section{Introduction}

Adjuvant chemotherapy can significantly improve disease-free survival (DFS) and overall survival (OS) for early breast cancer patients. However, adjuvant chemotherapy can cause many long-term side effects, such as chemotherapy-induced amenorrhea (CIA)., ${ }^{1,2}$

The incidence of CIA associated with regimens involving cyclophosphamide or anthracyclines ranges from 53-89\%. And the incidence of amenorrhea reported from the recently presented BCIRG-01 trial comparing TAC; (Docetaxel, Doxorubicin, and cyclophosphamide) and FAC; (5-FU, Doxorubicin, and Cyclophosphamide) in early-stage breast cancer was $32.8 \%$ in patients receiving FAC. However, this trial was presented at an early stage of follow-up, and the method of assessment was not reported. ${ }^{3,4}$

The definition of CIA varies among different studies but it is usually defined as cessation of menses for 3 consecutive cycles in a regularly menstruating female, it could be classified in to temporary and permanent CIA, and it is also could be classified in to early CIA: (which occurs within one year from starting of treatment) and late CIA: (which occurs after one year from starting the treatment). ${ }^{5}$

The human ovary is under the control of the hypothalamicpituitary-ovarian axis. The hypothalamus secrets gonadotropinreleasing hormone $(\mathrm{GnRH})$ which stimulates the pituitary gland to secret gonadotropins; FSH and LH, which stimulate the growth of ovarian follicles and the ovulation. The high levels of estradiol and progesterone suppress the pituitary gonadotropins by negative feedback mechanism. This mechanism occurs in a cyclic pattern repeated monthly and known as ovarian cycle. ${ }^{6}$ Ovarian follicles are vulnerable to agents that cause DNA damage such as chemotherapy, so Chemotherapy reduces primordial follicle reserves, which can result in immediate ovarian failure. ${ }^{7-9}$

Endocrine hormonal profiles obtained from premenopausal patients treated with adjuvant chemotherapy who develop chemotherapyinduced amenorrhea (CIA) are consistent with primary ovarian failure; Estradiol and progesterone levels remain persistently low and cease to show their normal cyclic changes. ${ }^{10-12}$ As mentioned before, this CIA could be temporary, and many patients who developed CIA may regain menses again. And if we have a method to confirm true menopause in 
patients who develop CIA, we could use aromatase-inhibitors as an adjuvant hormonal treatment in those patients based on the data from ATAC (Arimidex, Tamoxifen, Alone or in Combination) trial which showed superior results of aromatase-inhibitors over Tamoxifen in postmenopausal breast cancer patients. ${ }^{13}$ In this study, the hormonal changes in the serum of the premenopausal early stage breast cancer patients who developed CIA was recorded for one year, to find a way to predict true menopause in those patients.

\section{Material and methods}

This study is a prospective study which was conducted in the Medical Research Institute, Alexandria. It included premenopausal, early stage breast cancer patients who developed CIA with adjuvant FAC chemotherapy. The accrual of cases started from February 2010 and ended in February 2011. Then the collection and analysis of data were done at February 2012. Informed consent was obtained from patients included in the study.

\section{Inclusion criteria}

i. Early stage breast cancer patient; stage I, II, IIIA.

ii. Premenopausal and history of regular menstruation.

iii. Undergone surgical excision for her breast tumor; either conservative breast surgery or modified radical mastectomy.

iv. Starting adjuvant FAC.

v. Recorded amenorrhea after starting FAC.

\section{Treatment}

i. FAC chemotherapy (5-Flourouracil $500 \mathrm{mgm} / \mathrm{m}^{2}$, Adriamycin $50 \mathrm{mgm} / \mathrm{m}^{2}$, Cyclophosphamide $500 \mathrm{mgm} / \mathrm{m}^{2}$ every 21 days for 6 cycles).

ii. Adjuvant loco-regional radiotherapy when indicated; (45Gy/25 fractions).

iii. Adjuvant tamoxifen tablets (20mg daily) if the tumor exhibit Estrogen receptor positivity in pathology report.

\section{Intervention and follow-up schedule}

The included patients were subjected to history taking, clinical examination, and metastatic work-up: (chest x-ray, ultrasound abdomen and pelvis, and bone scan if indicated), Starting adjuvant FAC chemotherapy (with or without radiotherapy) then starting Tamoxifen if hormonal receptors are positive in their tumor. Pregnancy test in urine using commercially available dipsticks, once the patient recorded amenorrhea, to exclude pregnancy as a cause of this recorded amenorrhea.

Estimating blood levels of Estradiol $\left(\mathrm{E}_{2}\right)$ and follicular stimulating hormone (FSH) after excluding pregnancy. The blood sampling was done and analyzed in the Department of Chemical pathology in The Medical Research Institute, and the measured units used by this lab was $\mathrm{pg} / \mathrm{ml}$ for $\mathrm{E}_{2}$ and IU/L for FSH. Then a re-evaluation was done after 6month and one year from the date of recording amenorrhea, the blood levels of $\mathrm{E}_{2}$ and FSH was measured in these visits and results was recorded. Then data was collected and presented in tables and figures for statistical analysis.

The statistical analysis was done by using SPSS v.15 soft ware. A Wilcoxon signed ranks test was used to evaluate the relation and/ or the difference between the mean $\mathrm{E}_{2}$ and FSH levels at different periods; first time, after 6 month and after one year. A Monte Carlo test was used to evaluate the relation between $\mathrm{E}_{2}$ and FSH levels and the chance of regaining mensis. The test was statistically significant if the $P$ value is 0.05 or less.

\section{Results}

From February 2010 to February 2011, there were only 67 eligible patients. And by the end of February 2012, there were only 50patients with complete data, as the other 17 eligible patients loss follow up.

\section{Patient's demographic characteristics}

Age: The age of those 50patients ranged from 33years to 51years (mean 45.88), the number of patients who are below or equal to 35 years was 2 patients only ( $4 \%$ ), the number of patients who are more than $35 y$ years to $40 y$ ears was also 2 patients $(4 \%)$, and the number of patients who are above 40years age was 46patients (92\%) (Table 1).

Table I Distribution of patients according to age

\begin{tabular}{lll}
\hline Age & No. & $\%$ \\
\hline$\leq 35$ & 2 & 4 \\
$>35-40$ & 2 & 4 \\
$>40$ & 46 & 92
\end{tabular}

Pathologic subtype: 47patients had invasive-ductal carcinoma and 3 patients had invasive-lobular carcinoma.

Grade: 48patients had grade II tumor

Stage: 32patients were stage IIA disease, 9patients were stage IIB and 8patients were stage IIIA disease.

Margin status: 38patients had positive vascular invasion.

Hormonal receptors status: all patients were estrogen receptor (ER) positive.

Treatment: all patients completed 6 cycles FAC, then started tamoxifen tablets. Our patients did not received LHRH analogues as they were already developed amenorrhea and the consultants in our institute did not recommend LHRH analogues for them.

\section{Timing of amenorrhea with chemotherapy}

The majority of patients showed amenorrhea after the second cycle of chemotherapy; 22patients (44\%), the number of patients who showed amenorrhea after the fourth and third cycle were 9patients(18\% ) and 8patients $(16 \%)$ respectively. The number of patients who showed amenorrhea after fifth cycle were $4(8 \%)$, and after sixth cycle were also $4(8 \%)$, and few patients showed amenorrhea after first cycle, they were 3 patients only $(6 \%)$; Table 2 .

Table 2 Time of amenorrhea

\begin{tabular}{lll}
\hline Time of amenorrhea & No. & $\%$ \\
\hline First cycle & 3 & 6 \\
Second cycle & 22 & 44 \\
Third cycle & 8 & 16 \\
Fourth cycle & 9 & 18 \\
Fifth cycle & 4 & 8 \\
Sixth cycle & 4 & 8 \\
\hline
\end{tabular}




\section{Changes in the $E_{2}$ and FSH levels during follow up}

The estradiol $\left(\mathrm{E}_{2}\right)$ levels decreased once the amenorrhea was recorded $($ mean $=37.79 \mathrm{pg} / \mathrm{ml})$ and the follicular-stimulating hormone (FSH) levels increased $($ mean $=55.97 \mathrm{mIU} / \mathrm{ml})$. These changes in both $\mathrm{E}_{2}$ and $\mathrm{FSH}$ are similar to the changes occurring in women with primary ovarian failure; $\left(\mathrm{E}_{2}<20\right.$ and $\left.\mathrm{FSH}>40\right)$.

Then, after six months from development of chemotherapyinduced amenorrhea the $\left(E_{2}\right)$ levels increased $($ mean $=63.72)$ and the FSH levels decreased (mean=46.1). After one year, the $\left(\mathrm{E}_{2}\right)$ levels increased more $($ mean $=67.96)$ and the levels of FSH decreased (mean=25.11). Table 3 shows the distribution of patients according to $\mathrm{E}_{2}$ levels in $\mathrm{pg} / \mathrm{ml}$ during follow-up.

Table 3 Distribution of patients according to level of E2

\begin{tabular}{lllllll}
\hline & \multicolumn{2}{l}{ E2 } & & \multicolumn{2}{l}{} \\
\cline { 2 - 7 } & \multicolumn{2}{l}{ I $^{\text {st }}$ time } & \multicolumn{2}{l}{ 6months } & \multicolumn{2}{l}{ lyear } \\
\cline { 2 - 7 } & No. & $\%$ & No. & $\%$ & No. & $\%$ \\
\hline$<20 \mathrm{pg} / \mathrm{ml}$ & 27 & 54 & 22 & 44 & 21 & 42 \\
$20-50$ & 15 & 30 & 20 & 40 & 4 & 8 \\
$>50$ & 8 & 16 & 8 & 16 & 25 & 50 \\
\hline
\end{tabular}

Table 4 shows the distribution of patients according to FSH levels in $\mathrm{mIU} / \mathrm{ml}$ during follow-up. There is a statistically significant relation between the $\mathrm{E}_{2}$, FSH levels and the possibility of regaining menses after CIA; patients with FSH levels more than or equal to 40IU/L, and/or estradiol levels less than $20 \mathrm{pg} / \mathrm{ml}$ at the time of first recording of amenorrhea, not regained their normal menses again for at least one year, and in some patients, for 18 months which was the maximum duration of follow up after recording amenorrhea with chemotherapy. This will be shown in Table $5 \&$ Table 6 , which also showed that only 5 patients had temporary CIA.

Table 4 Distribution of patients according to level of FSH

\begin{tabular}{|c|c|c|c|c|c|c|}
\hline & \multicolumn{6}{|c|}{ FSH } \\
\hline & \multicolumn{2}{|c|}{ I $^{\text {st }}$ Time } & \multicolumn{2}{|c|}{6 Months } & \multicolumn{2}{|c|}{ I Year } \\
\hline & No. & $\%$ & No. & $\%$ & No. & $\%$ \\
\hline$<20$ & 5 & 10 & 5 & 10 & 24 & 48 \\
\hline $20-<40$ & 8 & 16 & 14 & 28 & 20 & 40 \\
\hline $40-60$ & 15 & 30 & 16 & 32 & 6 & 12 \\
\hline$>60$ & 22 & 44 & 15 & 30 & 0 & 0 \\
\hline
\end{tabular}

Table 5 The relation between the E2 levels at first time estimation and regaining of menses

\begin{tabular}{|c|c|c|c|c|c|c|c|c|}
\hline \multirow{2}{*}{\multicolumn{2}{|c|}{ 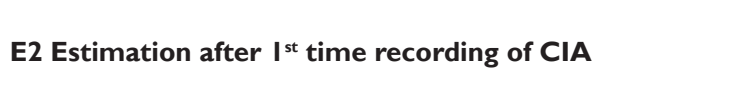 }} & \multicolumn{6}{|c|}{ E2 levels in pg/ml } & \multirow{2}{*}{$P$ value } \\
\hline & & \multicolumn{2}{|c|}{$<20$} & \multicolumn{2}{|c|}{$20-50$} & \multicolumn{2}{|c|}{$>50$} & \\
\hline \multirow{2}{*}{ Patients } & Who show amenorrhea for I8months of follow-up: & 27 & $100 \%$ & 14 & $93.30 \%$ & 4 & $50 \%$ & \multirow{2}{*}{$<0.001 *$} \\
\hline & Who regain menses during follow-up: & 0 & $0 \%$ & I & $6.70 \%$ & 4 & $50 \%$ & \\
\hline
\end{tabular}

Table 6 The relation between the FSH levels at first time estimation and regaining of menses

\section{FSH Estimation after I $^{\text {st }}$ time recording of CIA}

Who show amenorrhea for I8months of follow-up:
Patients Who regain menses during follow-up:

\section{Discussion}

In most patients, the hormonal profile is similar to that of women with primary ovarian failure; $\left(\mathrm{FSH}>40 \mathrm{IU} / \mathrm{L}\right.$ and $/$ or $\mathrm{E}_{2}<20 \mathrm{pg} / \mathrm{ml}$ ). And this finding was matched with many other studies in the literature.

In our study we did not evaluate pre-treatment hormonal levels because all patients included were regularly menstruating, this is indicating a normal hormonal profile in these patients. This was similar to the study which was done by Petrek et al. ${ }^{14}$ who depended on the clinical parameters and menstrual history only to evaluate the ovarian function in treated breast cancer patients. On the other hand, other studies did not estimate the hormonal profile once amenorrhea was recorded by the patients as we did in our study, this was the case in a study carried out by Poikonen et al. ${ }^{15}$ who measured the hormonal profile after one year from beginning of adjuvant chemotherapy.

In our study we evaluated $\mathrm{E}_{2}$ and FSH levels which was measured in the work of Poikonen et al..$^{15}$ but Rose et al. ${ }^{16}$ in his study evaluated total $\left(\mathrm{E}_{1}+\mathrm{E}_{2}\right)$ and FSH. The changes in $\mathrm{E}_{2}$ levels in our study matched with those in the work of Rose et al. ${ }^{16}$ and our results were similar to the results of the arm who received CMFPT (cyclophosphamide,

\begin{tabular}{|c|c|c|c|c|c|c|c|c|}
\hline \multicolumn{8}{|c|}{ FSH levels in IU/L } & \multirow{2}{*}{$P$ value } \\
\hline \multicolumn{2}{|c|}{$<20$} & \multicolumn{2}{|c|}{$20-<40$} & \multicolumn{2}{|c|}{$40-60$} & \multicolumn{2}{|c|}{$>60$} & \\
\hline I & $20 \%$ & 7 & $87.50 \%$ & 15 & $100 \%$ & 22 & $100 \%$ & $<0001 *$ \\
\hline 4 & $80 \%$ & I & $12.50 \%$ & 0 & $0 \%$ & 0 & $0 \%$ & \\
\hline
\end{tabular}

methotrexate, flurouracil, prednisilone, tamoxifen) in this study, that

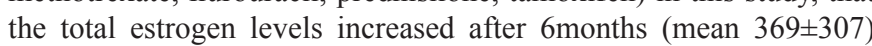
then it decreased after 10month evaluation (mean 194 \pm 205 ), this was explained by blocking of hypothalamic-estrogen receptors by tamoxifen, resulting in a failure of hormonal feed-back regulation of ovarian steroido-genesis by LH and FSH. Also our results matched with the results of Poikonen et al. ${ }^{15}$ as the median $\mathrm{E}_{2}$ after one year was $0.3 \mathrm{nmol} / 1$ in his study. Our study was not conducted on triplenegative patients as those patients are rare in our institute, in spite conducting study on those patients could eliminate the confounding effect of tamoxifen intake.

Also, in our study the changes in FSH levels matches with the work of Rose et al. ${ }^{16}$ in the arm who receive CMFPT in his study, that the FSH levels decreased after 6months (mean 54 \pm 54 ) then it increased after 10 month evaluation (mean $60 \pm 46$ ), this was accompanied by the changes in estrogen levels. This matched with the work of Lower et al. ${ }^{17}$ where the FSH level after chemotherapy was high $(59.1 \mathrm{IU} / \mathrm{L})$, and it decreased within 6month $(24.4 \mathrm{IU} / \mathrm{L})$, and also matched with the work of Poikonen et al. ${ }^{15}$ as the median FSH after one year was 63.2IU/L (range:10-97.9). He found as in our work, that the FSH level 
after one year was not a reliable indicator of the castration effect of adjuvant chemotherapy.

First time $\mathrm{E}_{2}$ and FSH levels can predict the reversibility of CIA in patients who developed this type of amenorrhea, that is to say that; with the $\mathrm{E}_{2}$ level of less than $20 \mathrm{pg} / \mathrm{ml}$, there was a very little probability for regaining menses, and with FSH levels of 40mIU/ML or more there was also a very little probability for regaining menses. However, further studies with more number of patients and longer duration of follow-up may help to support these results.

\section{Conclusion}

Patients with CIA showed a hormonal profile similar to that of primary ovarian failure; ( $\mathrm{FSH}>40 \mathrm{IU} / \mathrm{L}$ and $\left.\mathrm{E}_{2}<20 \mathrm{pg} / \mathrm{ml}\right)$. If the levels of FSH rise to the values equal or more than $40 \mathrm{IU} / \mathrm{L}$, and/or the $\mathrm{E}_{2}$ levels decreases to levels below $20 \mathrm{pg} / \mathrm{ml}$ the CIA tend to be permanent, at least for one year which was the maximum duration of follow up in our study. So we could predict the postmenopausal status in premenopausal early stage breast cancer patients after receiving adjuvant chemotherapy.

\section{Acknowledgements}

None,

\section{Conflict of interest}

The author declares no conflict of interest.

\section{References}

1. Effects of chemotherapy and hormonal therapy for early breast cancer on recurrence and 15-year survival: an overview of the randomised trials Lancet. 2005;365(9472):1687-1717.

2. Walshe JM, Denduluri N, Swain SM. Amenorrhea in premenopausal women after adjuvant chemotherapy for breast cancer. J Clin Oncol. 2006;24(36):5769-5779.

3. Di Cosimo S, Alimonti A, Ferretti G, et al. Incidence of chemotherapyinduced amenorrhea depending on the timing of treatment by menstrual cycle phase in women with early breast cancer. Ann Oncol 2004;5(7):1065-1071.

4. Nabholtz J, Pienkowski T, Mackey J. Phase III trial comparing TAC (docetaxel, doxorubicin, cyclophosphamide) with FAC (5-fluorouracil, doxorubicin, cyclophosphamide) in the adjuvant treatment of node positive breast cancer (BC) patients: interim analysis of the BCIRG 001 study. Proc Annu Meet Am Soc Clin Oncol. 2002;2002:141.
5. Bines J, Oleske DM, Cobleigh MA. Ovarian function in premenopausal women treated with adjuvant chemotherapy for breast cancer. $J$ Clin Oncol. 1996;14(5):1718-1729.

6. Stephanie HM Van Goozen, Victor M Wiegant, Erik Endert, et al. Psychoendocrinological assessment of the menstrual cycle: the relationship between hormones, sexuality, and mood. Archives of Sexual Behavior. 1997;26(4):359-382.

7. Shapiro CL, Recht A. Side effects of adjuvant treatment of breast cancer. N Engl J Med. 2001;344(26):1997-2008.

8. Zhou WB, Yin H, Liu XA, et al. Incidence of chemotherapy-induced amenorrhea associated with epirubicin, docetaxel and navelbine in younger breast cancer patients. BMC Cancer. 2010;10:281.

9. Okanami Y, Ito Y, Watanabe C, et al. Incidence of chemotherapy-induced amenorrhea in premenopausal patients with breast cancer following adjuvant anthracycline and taxane. Breast Cancer. 2011;18(3):182-188.

10. Dnistrian AM, Schwartz MK, Fracchia AA, et al. Endocrine consequences of CMF adjuvant therapy in premenopausal and postmenopausal breast cancer patients. Cancer. 1983;51(5):803-807.

11. Dowsett M, Richner J. Effects of cytotoxic chemotherapy on ovarian and adrenal steroidogenesis in pre-menopausal breast cancer patients. Oncology. 1991;48(3):215-220.

12. Murugesan K, Rao SV, Vij U, et al. Effect of chemotherapy on gonadal function in women with breast cancer. Indian J Med Res. 1988;87:42-45.

13. Cuzick J, Sestak I, Baum M, et al. Effect of anastrozole and tamoxifen as adjuvant treatment for early-stage breast cancer: 10-year analysis of the ATAC trial. Lancet Oncol. 2010;11(12):1135-1141.

14. Petrek JA, Naughton MJ, Case LD, et al. Incidence, time course, and determinants of menstrual bleeding after breast cancer treatment: A prospective study. J Clin Oncol. 2006;24(7):1045-1051.

15. Poikonen P, Saarto T, Elomaa I, et al. Prognostic effect of amenorrhoea and elevated serum gonadotropin levels induced by adjuvant chemotherapy in premenopausal node-positive breast cancer patients. Eur $J$ Cancer. 2000;36(1):43-48.

16. Rose D. Effect of cytotoxic agents and anti-hormonal therapy on endocrine function. In: Bulbrook RD, et al. editors. Commentaries on Research in Breast Disease. 1979;1:111-145.

17. Lower EE, Blau R, Gazder P, et al. The risk of premature menopause induced by chemotherapy for early breast cancer. J Womens Health Gend Based Med. 1999;8(7):949-954. 